\title{
Clostridium difficile outbreaks: prevention and treatment strategies
}

This article was published in the following Dove Press journal:

Risk Management and Healthcare Policy

2 July 2012

Number of times this article has been viewed

\author{
Fernando J Martinez' \\ Daniel A Leffler ${ }^{2}$ \\ Ciaran P Kelly ${ }^{2}$ \\ 'Division of Gastroenterology, \\ Department of Medicine, University \\ of Miami, Miller School of Medicine, \\ Miami, FL, USA; '2Department of \\ Gastroenterology, Beth Israel \\ Deaconess Medical \\ Center, Harvard Medical School, \\ Boston, MA, USA
}

\begin{abstract}
The incidence and severity of Clostridium difficile infection (CDI) have increased dramatically over the past decade. Its treatment, however, has largely remained the same with the exception of oral vancomycin use as a first-line agent in severe disease. From 1999 to 2004, 20,642 deaths were attributed to CDI in the United States, almost 7 times the rate of all other intestinal infections combined. Worldwide, several major CDI outbreaks have occurred, and many of these were associated with the NAP1 strain. This 'epidemic' strain has contributed to the rising incidence and mortality of CDI. The purpose of this article is to review the current management, treatment, infection control, and prevention strategies that are needed to combat this increasingly morbid disease.
\end{abstract}

Keywords: antibiotic, antimicrobial, infectious colitis, pseudomembranous colitis, nosocomial, iatrogenic, toxin, Clostridium difficile

\section{Introduction to Clostridium difficile outbreaks}

Clostridium difficile is a Gram-positive, anaerobic, spore-forming, toxin-producing bacillus that causes antibiotic-associated diarrhea and colitis. It is transmitted via the fecal-oral route among humans. It was first isolated in 1935 by Hall and O'Toole from the stool of healthy neonates. ${ }^{1}$ They chose the name 'difficile' because of the difficulty they had in culturing this anaerobic bacterium on conventional media. At that time, it was not known to cause disease in human beings although cytotoxin production was recognized. In the late $1970 \mathrm{~s}, C$. difficile toxins were identified as the main causative agents in antibiotic-associated pseudomembranous colitis.

Over the past 20 years, the incidence and severity of $C$. difficile infection (CDI) have increased substantially. This pathogen is now associated with a far higher incidence of hospitalizations than the more widely publicized methicillin-resistant Staphylococcus aureus. ${ }^{2}$ CDI can cause a spectrum of disease ranging from asymptomatic carriage to mild diarrhea to pseudomembranous colitis with sepsis, toxic megacolon, organ failure, and death. The rate of US hospital discharges with CDI listed as a diagnosis doubled from $31 / 100,000$ population in 1996 to $61 / 100,000$ in 2003 . The rate was sevenfold higher in persons $>65$ years of age compared to the 45-64 years age group. ${ }^{2}$ Mortality rates related to CDI also increased during the same time period, rising from 5.7 deaths per million population in 1999 to 23.7 deaths per million population in 2004, an increase of about 35\% per year. ${ }^{3}$ From 1999 to 2004, CDI was reported as a cause of death in 20,642 persons in the United States, almost 7 times the rate of all other intestinal infections combined. ${ }^{3}$ In England, the UK Statistics Authority listed CDI as the primary cause of death in 499 people in 1999, a number that more than
Correspondence: Ciaran P Kelly Department of Gastroenterology, Beth Israel Deaconess Medical Center, Harvard Medical School, 330 Brookline Ave, Dana 60I, Boston, MA 02215, USA Tel + I 617667 I264

Email ckelly2@bidmc.harvard.edu 
tripled to 1998 in 2005 and then rose further to 3393 in $2006 .{ }^{4}$ The causes of these dramatic increases in CDI incidence and mortality seem to be multifactorial resulting from an aging hospital population with complex comorbidities, ever increasing antibiotic use, and the emergence of more virulent strains including the BI/NAP1/027/toxinotype III strain - henceforth designated as NAP1. ${ }^{5-7}$

Several outbreaks of CDI occurred in 6 different states in the United States between 2000 and 2003. ${ }^{7}$ The majority of isolates from the outbreaks belonged to the NAP1 strain of $C$. difficile, which was first characterized in the 1980s. A major difference in the newer NAP1 isolates when compared to earlier isolates was that the newer isolates exhibited high-level resistance to fluoroquinolones. ${ }^{7}$ A similar NAP1 CDI outbreak also occurred in Quebec, Canada, in 2004. The incidence of CDI in Quebec had increased from 6 per 1000 admissions in 1997 to 22.5 per 1000 admissions in 2004. The case-fatality rate of CDI also increased, rising from $1.5 \%$ of cases in 1997 to $6.9 \%$ in $2004 .{ }^{5}$ An analysis of 157 stool isolates from this outbreak, which included most major hospitals in the Quebec area, showed that $83 \%$ (129 isolates) of the cases were due to the new NAP1 strain. The emergence of the new NAP1 strain coincides with the rising incidence and mortality of CDI and highlights the need for better prevention and treatment strategies for this reemerging pathogen.

\section{Natural history and clinical presentation}

The life cycle of $C$. difficile begins in the spore form. These spores are easily transmitted as they are resistant to heat, acid, and antibiotics. The spores can remain viable for months outside of the human body. In the hospital, they can be found on bedding, furniture, medical equipment, as well as on the skin and jewelry of caregivers. ${ }^{8}$ Once ingested, the spores pass through the upper digestive tract into the intestines where they can germinate and colonize the colon. A study showed that $21 \%$ of patients receiving antibiotics and admitted to a general medical ward were colonized by this bacterium. ${ }^{9}$ Healthy individuals are usually protected from CDI by the normal bacterial flora of the gut, which resists C. difficile's colonization and growth. Disruption of the normal microflora by antibiotics allows $C$. difficile to proliferate, produce toxins, and cause disease. ${ }^{10} C$. difficile induces diarrhea and colitis through the release of two protein exotoxins, toxin A and toxin B. Greater than $60 \%$ of the population has serum and colonic antibody responses to these toxins. ${ }^{11,12}$ Low or absent concentrations of serum IgG antibody against
C. difficile toxins has been shown to confer a greater risk of CDI among hospitalized patients who become colonized by this bacterium. ${ }^{13}$ Toxigenic $C$. difficile can be identified in more than $95 \%$ of pseudomembranous colitis cases and in $15 \%-25 \%$ of antibiotic-associated diarrhea cases. ${ }^{14,15}$

The NAP1 strain was first identified in the 1980s by restriction endonuclease analysis (then named $\mathrm{BI}$ ). ${ }^{5,7}$ The recent North American and Quebec outbreaks used North American Field Pulse Type Analysis and PCR ribotyping, and it is now referred to as NAP1, ribotype 027 , or $\mathrm{BI} / \mathrm{NAP} 1 / 027$. This strain is characterized by three potential virulence determinants. The first is a possible enhancement of toxin A and toxin B production. The two toxin genes are found on the pathogenicity locus - a 5-gene region that includes the genes for toxin $\mathrm{A}(t c d A)$ and toxin $\mathrm{B}(t c d B)$ as well as three ancillary or regulatory genes $(t c d C, t c d E$, and $t c d R$ ) (Figure 1). The genes for toxins $\mathrm{A}$ and $\mathrm{B}$ are regulated by $t c d R$ (positive regulator) and $t c d C$ (negative regulator). The outbreak strains from Quebec and the United States carry deletion mutations in the $t c d C$ inhibitory gene. The resulting loss of this inhibitory gene product has been postulated to increase toxin production. However, more recent data challenge this conclusion. ${ }^{16}$ The second important factor in the NAP1 outbreak strain is high-level fluoroquinolone resistance (marked resistance to gatifloxacin, moxifloxacin, and levofloxacin). Such resistance was not seen in the earlier isolates from the 1980s and the 1990s..$^{5,7}$ These fluoroquinolone antibiotics are used commonly in the hospital setting as first-line treatment for community-acquired pneumonia, urinary tract infection, and gastrointestinal infection. It is thought that the widespread use of these antibiotics is partly to blame for recent NAP1 CDI outbreaks. Analysis of risk factors in the Quebec outbreak showed that the odds ratio (OR) for fluoroquinolone use in patients with CDI when compared to control subjects was 3.9. Restricting and reducing the use of fluoroquinolones may be helpful in preventing and managing NAP1 outbreaks. A third potential virulence factor in this new strain is the presence of binary toxin. Binary toxin is encoded by $c d t A$ and $c d t B$ in a separate region called the CDT locus. It is thought that binary toxin might have an additive enterotoxic effect with toxins $\mathrm{A}$ and $\mathrm{B}$, but its role, if any, in the pathophysiology of $\mathrm{CDI}$ remains unclear.

C. difficile diarrhea and colitis usually present in patients who are undergoing antibiotic therapy (Figure 2). The most notorious antibiotics leading to this illness are clindamycin, ampicillin, amoxicillin, cephalosporins, and fluoroquinolones. It has been reported that up to $96 \%$ of 


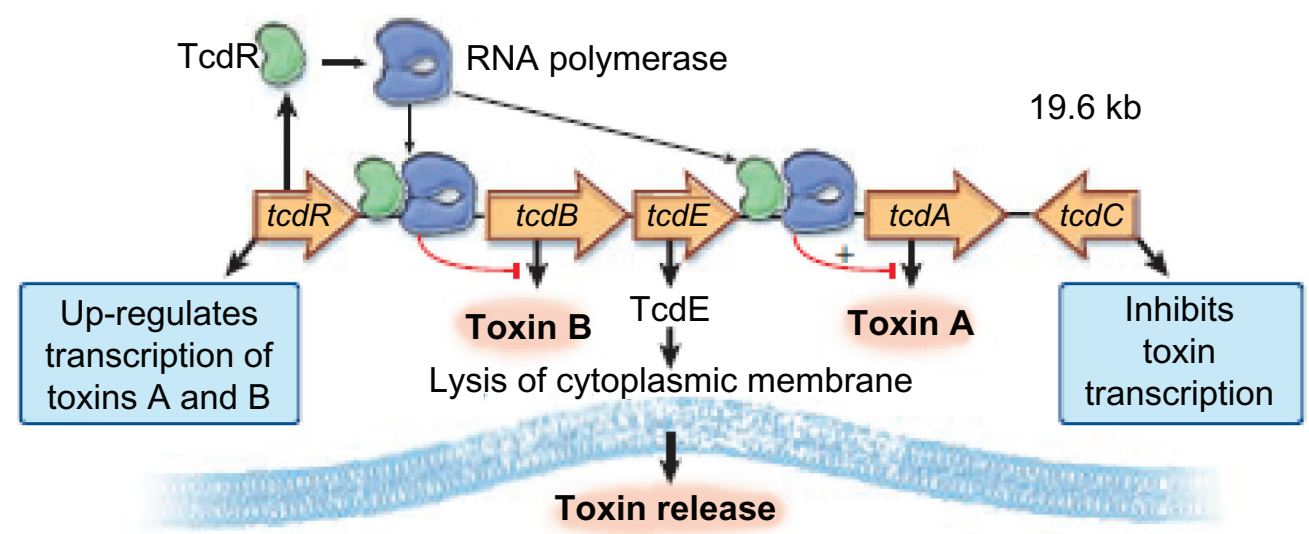

Figure I The pathogenicity locus of Clostridium difficile. The 19.6-kb pathogenicity locus encodes toxin A (tcdA), toxin B (tcdB), a positive regulator of toxin transcription $(t c d R)$, and a putative negative regulator of transcription $(t c d C)$. The function of the tcdE gene product is uncertain but may include the facilitation of toxin release by bacterial membrane lysis. The NAP- I/027 strain carries mutations in $t c d C$ that prevent the expression of TcdC protein.

Copyright (C) 2008, Massachusetts Medical Society. Modified with permission from Kelly CP, Lamont JT. Clostridium difficile - more difficult than ever. N Engl J Med. 2008; 359(18):1932-1940. ${ }^{36}$

patients with symptomatic CDI received antibiotics within 2 weeks of the onset of diarrhea. ${ }^{17}$ Other predisposing factors leading to disease include advanced age, nursing home residence, and hospitalization..$^{5,18}$ Recent data show that the use of acid suppressants are also associated with an increased risk of CDI. ${ }^{19,20}$ In the hospital, the most common presenting symptom of CDI is diarrhea, with the passage of frequent loose or watery stools. Occult blood and mucus can be seen but hematochezia and/or melena are rare. ${ }^{21}$ Patients can present with more serious signs and symptoms including colonic ileus or toxic megacolon.

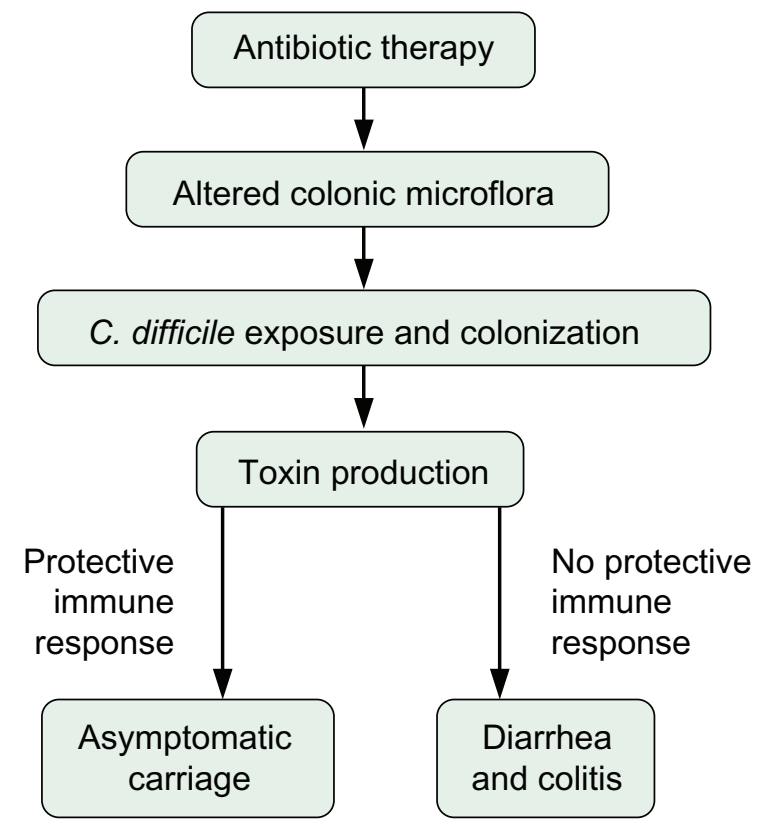

Figure 2 Pathogenesis of Clostridium difficile-associated diarrhea and colitis. Copyright (C) 200I, Elsevier. Reproduced with permission from Kyne L, Farrell R, Kelly CP. Clostridium difficile. Gastroenterol Clin North Am. 200I;30(3):753-777.22
The ileus prevents diarrhea from occurring so these patients can present with minimal or no diarrhea leading to delays in diagnosis. The only clues to the diagnosis of CDI in these cases may be fever, leukocytosis, and abdominal pain associated with diffuse abdominal tenderness to palpation and/or abdominal distention. Some patients may present with more fulminant disease, which can lead to shock, toxic megacolon, and/or multiorgan failure. The overall estimated case fatality rate of CDI is $>2 \%{ }^{23}$

CDI can be diagnosed based on clinical suspicion (usually diarrhea in a patient with current or recent antibiotic use) ideally supported by the demonstration of toxinogenic $C$. difficile or $C$. difficile toxins in the stool. ${ }^{24}$ The most widely used diagnostic tests are enzyme immunoassays (EIAs) to detect C. difficile toxins A and B. These EIAs are rapid (2-4 hours), relatively inexpensive, and convenient but show limited sensitivity with frequent falsely negative results. ${ }^{24,25}$ Accordingly, more sensitive tests including assays for clostridial glutamate dehydrogenase (used as an initial sensitive screening test with subsequent confirmation using a more specific assay), tissue culture cytotoxicity, and PCR are under evaluation as alternatives to toxin EIAs.

\section{Management and therapeutic strategies: efficacy of metronidazole and vancomycin as first choice of treatment}

The immediate goal of CDI therapy is to alleviate the active symptoms of diarrhea and colitis. The ultimate goal of treatment is the restoration of the normal bacterial flora of the gut and elimination of CDI. The ideal treatment for CDI 
would not require the use of antibiotics. Patients diagnosed with acute CDI should have all unnecessary antibiotics stopped. In 1974, Tedesco et al reported that up to $10 \%$ of patients receiving clindamycin suffered from pseudomembranous colitis. ${ }^{10}$ When clindamycin was discontinued, all patients recovered from their illness. However, many patients who suffer from CDI require antibiotic therapy to combat the growth of $C$. difficile and possibly also to treat serious coexisting infections.

The mainstays of treatment for CDI for the past 30 years have been metronidazole or oral vancomycin. Metronidazole is considered as first-line therapy for patients with mild to moderately severe CDI. Oral vancomycin has been reserved for patients who did not respond to or tolerate metronidazole, for patients with multiple recurrences of CDI, or for patients with severe disease. The published treatment failure rates of metronidazole and vancomycin before the year 2000 were similar (2.5\% and 3.5\%, respectively). After 2000, the published treatment failure rates of metronidazole rose to $18.2 \%$, while that of vancomycin remained low at $2.8 \% .^{26-28}$ This rise in treatment failure with metronidazole has coincided with the recent dramatic increases in CDI incidence and severity. These issues resulted in an ongoing debate in the medical community as to whether vancomycin is superior to metronidazole and should, therefore, be used as first-line therapy for CDI despite concerns about higher drug cost and possibly increased nosocomial vancomycin resistance, particularly in enterococci. ${ }^{30,31}$

In 2007, Zar et al reported the results of a randomized, double-blind, placebo-controlled trial of oral vancomycin versus metronidazole for the treatment of CDI. The study showed an overall treatment response rate of $84 \%$ (66/79 patients) in the metronidazole group and $97 \%$ (69/71 patients) in the vancomycin group. What was most novel and interesting in the study was that subjects were prospectively stratified based on CDI disease severity. In patients with mild disease, the overall response rate was slightly better in the vancomycin group (98\%) than in the metronidazole group (90\%), but the difference did not reach statistical significance $(P=0.36)$. Conversely, the response rate in subjects with severe disease was only $76 \%$ in the metronidazole group compared to $97 \%$ in the vancomycin group $(P=0.02) .{ }^{30}$ These data support the continued use of metronidazole in patients with mild CDI but indicate that oral vancomycin should be used as firstline therapy for patients who present with severe infection. Unfortunately, there is no widely accepted method to define mild or severe CDI, and further studies are needed to validate predictive rules to identify the patients most likely to respond to oral vancomycin. However, the authors propose the scheme illustrated in Table 1.

Table I Classification and treatment of initial Clostridium difficile infection

\begin{tabular}{|c|c|c|}
\hline Severity & Clinical manifestations & Treatment \\
\hline Carrier & No discernible clinical symptoms or signs & No treatment is indicated \\
\hline \multirow[t]{9}{*}{ Mild to moderate } & Mild diarrhea $<12$ stools/day & Discontinuation of predisposing antibiotics \\
\hline & Afebrile & Hydration \\
\hline & Mild to moderate abdominal discomfort or & Monitor clinical status \\
\hline & tenderness & Isolation \\
\hline & Nausea with rare or absent vomiting & Oral metronidazole $500 \mathrm{mg} 3$ times daily or intravenous \\
\hline & Leukocytosis $<20,000$ & metronidazole $500 \mathrm{mg} 3$ times daily if not tolerating \\
\hline & & 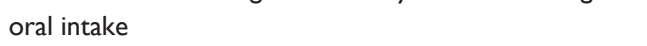 \\
\hline & & Oral vancomycin $125 \mathrm{mg} 4$ times daily if intolerant of \\
\hline & & metronidazole \\
\hline \multirow[t]{8}{*}{ Severe } & Severe diarrhea $>12$ stools/day & As above plus \\
\hline & Pseudomembranous colitis & Oral vancomycin $125 \mathrm{mg} 4$ times daily in place of oral \\
\hline & Severe abdominal pain & metronidazole \\
\hline & Nausea or vomiting & Consider addition of intravenous metronidazole \\
\hline & lleus & 500 mg 3 times daily \\
\hline & In intensive care unit & Intravenous metronidazole $500 \mathrm{mg} 3$ times daily if not \\
\hline & Leukocytosis $>20,000$ & tolerating oral intake \\
\hline & Renal failure & \\
\hline \multirow[t]{5}{*}{ Fulminant } & Toxic megacolon & As above plus \\
\hline & Peritonitis & Surgical consultation \\
\hline & Renal failure & Oral vancomycin $125 \mathrm{mg} 3$ times daily and \\
\hline & Respiratory distress & intravenous metronidazole 500 mg 3 times daily \\
\hline & Hemodynamic instability & Consider IVIG \\
\hline
\end{tabular}

Copyright (C) 2009, Elsevier. Modified with permission from Leffler DA, Lamont JT. Treatment of Clostridium difficile-associated disease. Gastroenterology. 2009; I36(6): 1899-1912.29 Abbreviations: BUN, blood urea nitrogen; IVIG, intravenous immunoglobulin. 
The standard initial therapy for mild CDI is to discontinue all antibiotics and monitor the patient's progress. For mild CDI that persists, when other antibiotics cannot be discontinued or when patients are frail, then metronidazole $500 \mathrm{mg}$ orally 3 times daily (or $250 \mathrm{mg}$ orally 4 times daily) is often used for 10-14 days (Table 2). In patients who are unable to tolerate oral administration, parenteral or rectal administration can be used and leads to similar systemic and colonic drug levels. The initial starting dose for vancomycin is $125 \mathrm{mg}$ orally 4 times daily for 10-14 days. Oral vancomycin is not degraded or absorbed by the gut and reaches the colon intact, which enables it to achieve high luminal concentrations with minimal toxicity. On the other hand, intravenous vancomycin is not secreted into the gut and is, therefore, not suitable for the treatment of CDI. In patients who cannot tolerate oral administration of vancomycin, intravenous metronidazole is the drug of choice. Vancomycin (500 mg 4 times daily) as rectal enemas or via a nasogastric tube can be used to supplement intravenous

Table 2 Suggested approaches to therapy

Initial episode
Mild to moderate infection
Metronidazole at a dose of $500 \mathrm{mg}$ orally 3 times daily for
I0-I 4 days
Severe infection or unresponsiveness to or intolerance to
metronidazole
Vancomycin at a dose of I 25 mg orally 4 times daily for I0-I4 days
First recurrence
Mild to moderate infection
Metronidazole at a dose of 500 mg orally 3 times daily for
I0-I 4 days
Severe infection or unresponsiveness to or intolerance to
metronidazole
Vancomycin at a dose of I 25 mg orally 4 times daily for I0-I4 days
Second recurrence:
Vancomycin in tapered and pulsed doses
I 25 mg daily 4 times daily for I 4 days
I 25 mg daily 2 times daily for 7 days
I 25 mg once daily for 7 days
I 25 mg once every 2 days for 8 days ( 4 doses)
I 25 mg once every 3 days for I 5 days ( 5 doses)
Third recurrence
Introncomycin at a dose of I 25 mg orally 4 times daily for I 4 days,
once every 3 weeks for a total of 2 or 3 doses
Therapy with other microorganisms, including 'fecal transplantation'
Intions for recurrent infection

Notes: ${ }^{a} \mathrm{~A}$ probiotic such as Saccharomyces boulardii or lactobacillus species may be added during the final 2 weeks of the vancomycin taper and for at least 4 weeks thereafter (preferably 8 weeks). However, the efficacy of probiotics in preventing recurrent $C$. difficile infection is unclear.

Copyright (c) 2008, Massachusetts Medical Society. Reproduced with permission from Kelly CP, Lamont JT. Clostridium difficile - more difficult than ever. N Engl J Med. 2008;359(18):1932-1940. ${ }^{36}$ metronidazole in patients with very severe CDI, who are unable to tolerate oral vancomycin. ${ }^{24,25,32}$

A difficult problem with CDI is recurrent infection, which occurs in $\sim 15 \%-30 \%$ of patients who were successfully treated with an initial course of metronidazole or vancomycin..$^{33,34}$ The clinical features of recurrence are similar to the initial occurrence with the presence of diarrhea occurring usually within 2 weeks after discontinuation of therapy. However, recurrences can occur up to 3 months after stopping the initial antibiotic treatment. Patients with mild symptoms can be treated conservatively with symptomatic management. Patients who require antibiotics are typically treated with a second course of the same antibiotic used to treat the initial attack, and this approach has a success rate of about $60 \%$. Probiotics (such as Lactobacillus spp. or Saccharomyces boulardii) may be used as an adjunctive therapy and may have some, limited efficacy in preventing recurrence. ${ }^{33}$ Patients who are intolerant to metronidazole should be placed on oral vancomycin at a dose of $125 \mathrm{mg} 4$ times daily and should be treated for a 14-day course. Unfortunately, despite successful treatment of a first recurrence $45 \%$ of these patients will have a repeat occurrence. Multiple recurrences are usually treated with a prolonged tapering course of oral vancomycin (Table 2). A suggested therapy for a second recurrence is the tapered and pulsed dosing of oral vancomycin over 51 days (Table 2 ). There are no established guidelines for the treatment of further recurrences, but other agents, such as intravenous immunoglobulins, rifaximin, probiotics, or fecal transplantion, have all been reported to be useful in uncontrolled studies. ${ }^{33,35-37}$ A newer promising treatment for prevention of recurrent CDI was recently published by Lowy et al. ${ }^{38}$ This was a randomized, double-blind, placebo-controlled trial of two human monoclonal antibodies against $C$. difficile toxins A (CDA1) and B (CDB1). The antibodies were administered in conjunction with metronidazole or vancomycin in patients receiving treatment for symptomatic CDI. The rate of recurrence was only $7 \%$ among patients treated with monoclonal antibodies versus $25 \%$ in the placebo group $(P \leq 0.001)$. The recurrence rate for patients infected with the BI/NAP1/027 strain was $8 \%$ for the monoclonal antibody group versus $32 \%$ in the placebo group $(P=0.06)$. Once commercially available, this monoclonal antibody will likely be used in patients at high risk for recurrent CDI. Risk factors for recurrent CDI include low serum IgG antitoxin, a prior recurrence, older age, severe underlying medical conditions, or a requirement for concomitant antibiotic treatment for additional infections. ${ }^{34,39}$ 


\section{Infection control and prevention strategies}

The ultimate goal in combating disease is prevention and/or eradication. Previous studies have suggested the efficacy of specific infection-control measures in reducing the incidence of CDI. These include hand hygiene, contact precautions, environmental cleaning and disinfection, and restriction of antimicrobial use. ${ }^{24,25}$ Nonetheless, the recent epidemics of CDI bring to light the need for better preventive measures. C. difficile vaccines are in development but are not ready for use in the population. ${ }^{40}$ Therefore, the current focus remains on infection control.

In June 2000, a C. difficile outbreak occurred at a teaching hospital in Pittsburgh, PA. ${ }^{18}$ This outbreak resulted in 26 colectomies and 18 deaths. In response, a C. difficile prevention bundle was instituted and was followed by a $78 \%$ decrease in the rate of CDI as well as a decrease in the number of severe CDI cases. ${ }^{41}$ The prevention bundle consisted of education, increased and early case finding, expanded infection-control measures, development of a CDI management team, and antimicrobial management. The education component consisted of a standardized education module with printable handouts for patients and providers. Nurses were given the authority to order testing for CDI, which allowed increased case finding. An e-mail alert system was also instituted, which encouraged attending physicians to test patients who were at high risk of having CDI. Expanded infection-control measures included environmental cleaning with bleach, electronic flags and alerts, hand hygiene with soap and water, prolonged duration of contact precautions beyond resolution of diarrhea, and infection-control audits. Finally, a formal antimicrobial management program was instituted, which required the prior approval of certain high-risk antibiotics by infectious diseases physicians and pharmacists. ${ }^{41}$

A similar bundle approach was recently instituted at a teaching hospital in Boston, MA. This study was an observational before-after study of adult patients admitted to a tertiary university-affiliated hospital during a 4-year period from January 2004 to December 2008. ${ }^{42}$ The intervention included an educational campaign, a prevention bundle, and a treatment bundle. The educational campaign taught all hospital personnel about the increasing incidence and severity of CDI and encouraged everyone to increase their level of suspicion for this diagnosis. The campaign encouraged hospital personnel to promptly initiate diagnostic testing, isolation precautions (including hand washing), and treatment for those diagnosed with
CDI. The prevention bundle gave specific responsibilities to physicians, physician assistants, nurse practitioners, floor nurses, microbiology staff, infection-control practitioners, and environmental services personnel (Table 3 ). The bundle also included specific infection-control practices: 1) 'Contact Precautions Plus' that included emphasizing hand washing after every encounter with a patient with CDI and cleaning rooms with hypochlorite-based disinfectant after a patient with CDI was discharged. 2) Laboratory notification procedures that included verbal notification to floor nurses, e-mail alerts to hospital infections preventionists when a patient had a positive toxin assay and steps to be taken in coordinating infection control, and environmental services that aimed to decrease the transmission of $C$. difficile between patients. 3) A treatment bundle was created to standardize the treatment of patients with severe CDI and to provide guidelines for when to consider surgical consultation. The incidence rate of health care-associated CDI decreased by $40 \%$ from 1.1 cases per 1000 patient days preintervention to 0.66 cases per 1000 patient days postintervention. This reduction was sustained over a 21-month period.

Hand hygiene is an important component of most hospital infection control and prevention programs. ${ }^{43-46}$ In many hospitals in the United States, the use of alcohol-based hand gels now far exceeds hand washing with soap and water as the primary hand hygiene method. One reason for the increased use of alcohol-based hand gels is that they are quick and effective. ${ }^{44}$ Proper hand hygiene is crucial in preventing the transmission of C. difficile in the hospital setting. In 1989, McFarland et al showed that $59 \%$ of hospital personnel caring for patients with a positive $C$. difficile culture carried the organism on their hands. ${ }^{9}$ It is well known that alcohol-based hand gels do not kill the $C$. difficile spores. A recent study by Oughton et al evaluated different hand hygiene methods for efficacy in removing $C$. difficile. The study examined 10 volunteers with hands experimentally contaminated by nontoxigenic $C$. difficile. The results showed that the greatest reduction of $C$. difficile colony counts occurred by hand washing with soap and water, while the use of alcohol-based handrub was equivalent to no intervention. ${ }^{47}$ It is difficult to determine whether the increased usage of alcohol-based gels has played a role in the increasing incidence of $C$. difficile. Regardless, the current data provide preliminary support for the use of soap and water over hand gels for hospital personnel who are in contact with a $C$. difficile-infected patient.

Another important vector for the transmission of $C$. difficile is through the hospital environment. 
Table 3 Clostridium difficile Infection (CDI) checklist

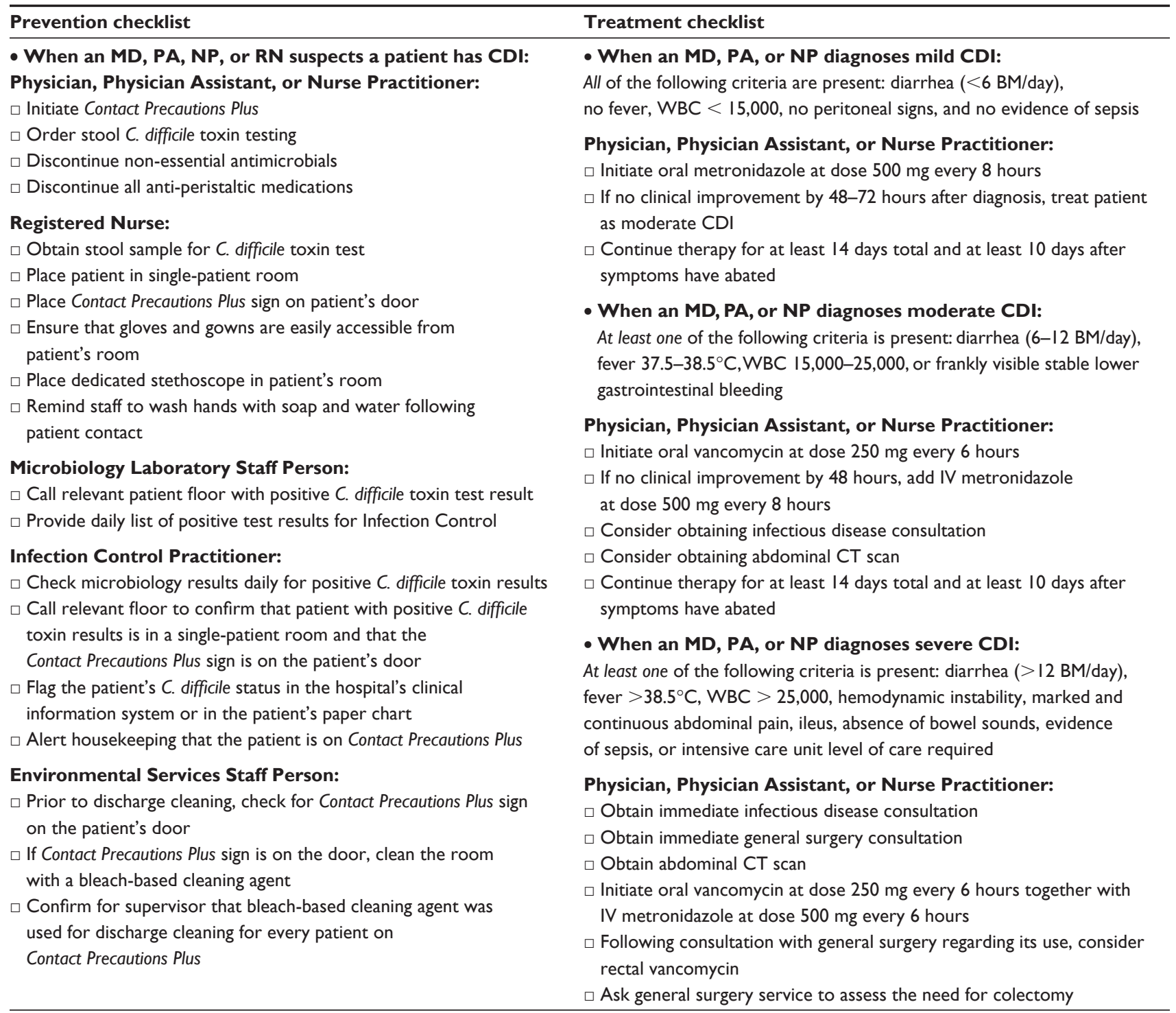

Hospital interventions to decrease the incidence and mortality of healthcare-associated $C$. difficile infections.

Notes: After the institution of this checklist along with other interventions, there was a $40 \%$ reduction in the incidence of CDI at this Boston hospital.

Copyright @ 2009 , University of Chicago Press. Reproduced with permission from Abbett SK, Yokoe DS, Lipsitz SR, et al. Proposed checklist of hospital interventions to decrease the incidence of healthcare-associated Clostridium difficile infection. Infect Control Hosp Epidemiol. 2009;30(II): 1062-1069.42

Abbreviations: MD, medical doctor; PA, physician assistant; NP, nurse practitioner; RN, registered nurse; BM, bowel movement; WBC, white blood cell count; $\mathrm{CT}$, computed tomography; IV, intravenous.

C. difficile can be found in the hospital on floors, bedrails, windowsills, commodes, toilets, call buttons, blood pressure cuffs, electronic thermometers, and bedsheets. ${ }^{48}$ Therefore, disinfection of the contaminated hospital environment is essential to prevent the transmission of this nosocomial pathogen. Quaternary ammonium-based disinfectants are used commonly in the hospital setting but are not sporicidal against $C$. difficile. ${ }^{48,49}$ Disinfectants containing unbuffered hypochlorite (bleach), on the other hand, are sporicidal. ${ }^{49,50}$ In 1988, Kaatz et al reported on the use of hypochlorite as a disinfectant during a $C$. difficile outbreak. The bacterium was recovered from $31 \%$ of environmental cultures obtained on the hospital wards. These wards were then disinfected with unbuffered hypochlorite, and the outbreak subsequently ended. ${ }^{51} \mathrm{~A}$ more recent study by Fawley et al compared the effects of five different cleaning agents against epidemic and nonepidemic $C$. difficile strains. This study showed that only chlorine-based germicides were able to inactivate C. difficile spores. ${ }^{52}$ These studies support the use of chlorine-based disinfectants for preventing the transmission of $C$. difficile.

Another potential prevention measure in the fight against C. difficile could be the restriction of acid-suppressive agents. Recent literature suggests that there is an association 
between the use of proton pump inhibitors (PPIs) and CDI, ${ }^{19,20}$ and multiple large studies now support this finding. ${ }^{53-55}$ Cunningham et al showed that PPI use within the preceding 8 weeks prior to exposure was associated with an increased risk of $C$. difficile diarrhea, OR of 2.5 , and $95 \%$ confidence interval (CI) of 1.5-4.2. ${ }^{20}$ In 2008, Aseeri et al reported similar results in a case control study, where CDI was associated with the use of PPI with an OR of 3.6 and $95 \%$ CI of $1.7-8.3 .{ }^{56}$ The pathophysiology behind this association is not well understood, as $C$. difficile spores are known to be acid-resistant. $C$. difficile should be able to pass through the stomach despite its acidic environment, so it is unclear as to how acid suppression might increase the risk of developing infection. Hypotheses include C. difficile-permissive changes in intestinal flora with increasing $\mathrm{pH}^{57}$ or potentially that the use of acid suppressants is a marker for comorbidity, a well-established risk factor for CDI. ${ }^{58,59}$

The role of probiotics in the prevention of $C$. difficile remains unclear. ${ }^{60,61}$ There are many studies in the literature regarding probiotics in the prevention of antibiotic-associated diarrhea, but fewer studies looking at probiotics in the prevention of CDI. In 2004, Plummer et al reported a double-blind, placebo-controlled trial examining the role of probiotics (Lactobacillus and Bifidobacterium) in the prevention of CDI. ${ }^{62}$ In this study, 150 consecutive patients receiving antibiotic therapy were randomized to receiving the probiotic or placebo. The results showed that, on the basis of developing diarrhea, only $2.9 \%$ of stool samples in the probiotic group were positive for $C$. difficile-associated toxins versus $7.25 \%$ in the placebo-controlled group. Despite this finding, the total number of patients who tested positive for $C$. difficile was actually higher in the probiotic group $(n=11)$ than in the placebo group $(n=9)$, so the effect of the probiotic in this study is uncertain. S. boulardii does not appear to be effective in primary prevention of CDI..$^{33,63}$ At this time, there is insufficient evidence to support the widespread use of probiotics for the primary prevention of CDI. Larger randomized control trials are needed to support its use.

\section{Conclusion}

The incidence and severity of CDI has increased over the past decade, and this infection is associated with an increased mortality due to an aging population, increased antibiotic use, and increased bacterial virulence. Despite this increasing severity, the mainstay of treatment has changed very little. Metronidazole is appropriate for mild to moderately severe $\mathrm{CDI}$, while vancomycin is now recommended as first-line therapy for severe infection. Immune-based therapies, such as vaccines and passive immunotherapies, show promise but further studies need to be done. At this time, the focus of the medical community should be on prevention strategies. Infection-control programs are essential and should be multifaceted to control the increasing incidence of this morbid disease.

\section{Disclosure}

The authors report no conflicts of interest in this work.

\section{References}

1. Hall IC, O'Toole E. Intestinal flora in new-born infants: with a description of a new pathogenic anaerobe, Baccilus difficilis. Am J Dis Child. 1935;49(2):390-402.

2. McDonald LC, Owings M, Jernigan DB. Clostridium difficile infection in patients discharged from US short-stay hospitals, 1996-2003. Emerg Infect Dis. 2006;12(3):409-415.

3. Redelings MD, Sorvillo F, Mascola L. Increase in Clostridium difficile-related mortality rates, United States 1999-2004. Emerg Infect Dis. 2007;13(9):1417-1419.

4. United Kingdom National Statistics. Newport (UK): Office for National Statistics, UK Statistics Authority. Available from: http:// www.statistics.gov.uk. Accessed April 2, 2010.

5. Loo VG, Poirier L, Miller MA, et al. A predominantly clonal multi-institutional outbreak of Clostridium difficile-associated diarrhea with high morbidity and mortality. $N$ Engl J Med. 2005;353(23): 2442-2449.

6. O'Connor JR, Johnson S, Gerding DN. Clostridium difficile infection caused by the epidemic BI/NAP1/027 strain. Gastroenterology. 2009; 136(6):1913-1924.

7. McDonald LC, Killgore GE, Thompson A, et al. An epidemic, toxin gene-variant strain of Clostridium difficile. NEngl J Med. 2005;353(23): 2433-2441.

8. Fekety R, Kim KH, Brown D, Batts DH, Cudmore M, Silva J Jr. Epidemiology of antibiotic-associated colitis: isolation of Clostridium difficile from the hospital environment. Am J Med. 1981;70(4):906-908.

9. McFarland LV, Mulligan ME, Kwok RY, Stamm WE. Nosocomial acquisition of Clostridium difficile infection. $N$ Engl J Med. 1989; 320(4):204-210.

10. Tedesco FJ, Barton RW, Alpers DH. Clindamycin-associated colitis. A prospective study. Ann Intern Med. 1974;81(4):429-433.

11. Viscidi R, Laughton BE, Yolken R, et al. Serum antibody response to toxins A and B of Clostridium difficile. J Infect Dis. 1983;148(1):93-100.

12. Kelly CP, Pothoulakis C, Orellana J, LaMont JT. Human colonic aspirates containing immunoglobulin A antibody to Clostridium difficile toxin A inhibit toxin A-receptor binding. Gastroenterology. 1992;102(1):35-40.

13. Kyne L, Warny M, Qamar A, Kelly CP. Asymptomatic carriage of Clostridium difficile and serum levels of IgG antibody against toxin A. N Engl J Med. 2000;342(6):390-397.

14. Bartlett JG. Clostridium difficile: history of its role as an enteric pathogen and current state of knowledge about the organism. Clin Infect Dis. 1994;18 Supp1 4:S265-S272.

15. Barbut F, Petit JC. Epidemiology of Clostridium difficile-associated infections. Clin Microbiol Infect. 2001;7(8):405-410.

16. MacCannell DR, Louie TJ, Gregson DB, et al. Molecular analysis of Clostridium difficile PCR ribotype 027 isolates from Eastern and Western Canada. J Clin Microbiol. 2006;44(6):2147-2152.

17. Olson MM, Shanholtzer CJ, Lee JT Jr, Gerding DN. Ten years of prospective Clostridium difficile-associated disease surveillance and treatment at the Minneapolis VA Medical Center, 1982-1991. Infect Control Hosp Epidemiol. 1994;15(6):371-381. 
18. Muto CA, Pokrywka M, Shutt K, et al. A large outbreak of Clostridium difficile-associated disease with an unexpected proportion of deaths and colectomies at a teaching hospital following increased fluoroquinolone use. Infect Control Hosp Epidemiol. 2005;26(3):273-280.

19. Dial S, Alrasadi K, Manoukian C, Huang A, Menzies D. Risk of Clostridium difficile diarrhea among hospital inpatients prescribed proton pump inhibitors: cohort and case-control studies. CMAJ. 2004; 171(1):33-38.

20. Cunningham R, Dale B, Undy B, Gaunt N. Proton pump inhibitors as a risk factor for Clostridium difficile diarrhoea. J Hosp Infect. 2003;54(3): 243-245.

21. Kelly CP, Lamont JT. Antibiotic-associated diarrhea, pseudomembranous enterocolitis, and Clostridium difficile-associated diarrhea and colitis. In: Feldman M, Friedman LS, Brandt LJ, editiors. Sleisenger and Fordtran's Gastrointestinal and Liver Disease. 8th ed. Philadelphia (PA): Saunders; 2006:2393-2412.

22. Kyne L, Farrell R, Kelly CP. Clostridium difficile. Gastroenterol Clin North Am. 2001;30(3):753-777.

23. Zilberberg MD, Shorr AF, Kollef MH. Increase in adult Clostridium difficile-related hospitalizations and case-fatality rate, United States, 2000-2005. Emerg Infect Dis. 2008;14(6):929-931.

24. Cohen SH, Gerding DN, Johnson S, et al; Society for Healthcare Epidemiology of America; Infectious Diseases Society of America. Clinical practice guidelines for Clostridium difficile infection in adults: 2010 update by the Society for Healthcare Epidemiology of America (SHEA) and the Infectious Diseases Society of America (IDSA). Infect Control Hosp Epidemiol. 2010;31(5):431-455.

25. Crobach MJ, Dekkers OM, Wilcox MH, Kuijper EJ. European Society of Clinical Microbiology and Infectious Diseases (ESCMID): data review and recommendations for diagnosing Clostridium difficile-infection (CDI). Clin Microbiol Infect. 2009;15(12):1053-1066.

26. Musher DM, Aslam S, Logan N, et al. Relatively poor outcome after treatment of Clostridium difficile colitis with metronidazole. Clin Infect Dis. 2005;40(11):1586-1590.

27. Pepin J, Alary ME, Valiquette L, et al. Increasing risk of relapse after treatment of Clostridium difficile colitis in Quebec, Canada. Clin Infect Dis. 2005;40(11):1591-1597.

28. Aslam S, Hamill RJ, Musher DM. Treatment of Clostridium difficileassociated disease: old therapies and new strategies. Lancet Infect Dis. 2005;5(9):549-557.

29. Leffler DA, Lamont JT. Treatment of Clostridium difficile-associated disease. Gastroenterology. 2009;136(6):1899-1912.

30. Zar FA, Bakkangar SR, Moorthi KM, Davis MB. A comparison of vancomycin and metronidazole for the treatment of Clostridium difficile-associated diarrhea, stratified by disease severity. Clin Infect Dis. 2007;45(3):302-307.

31. Louie T, Gerdsom M, Grimard D, et al. Results of a phase III trial comparing tovelamer, vancomycin and metronidazole in patients with Clostridium difficile-associated diarrhea (CDI). Presented at the 47th Annual Interscience Conference on Antimicrobial Agents and Chemotherapy; 2007 Sep 17-20; Chicago. Abstract.

32. Apisarnthanarak A, Razavi B, Mundy LM. Adjunctive intracolonic vancomycin for severe Clostridium difficile colitis: case series and review of the literature. Clin Infect Dis. 2002;35(6): 690-696.

33. McFarland LV, Surawicz CM, Greenberg RN, et al. A randomized placebo-controlled trial of Saccharomyces boulardii in combination with standard antibiotics for Clostridium difficile disease. JAMA. 1994;271(24):1913-1918.

34. Kyne L, Warny M, Qamar A, Kelly CP. Association between antibody response to toxin $\mathrm{A}$ and protection against recurrent Clostridium difficile diarrhoea. Lancet. 2001;357(9251):189-193.

35. Wilcox MH. Descriptive study of intravenous immunoglobulin for the treatment of recurrent Clostridium difficile diarrheoa. J Antimicrob Chemother. 2004;53(5):882-884.

36. Kelly CP, Lamont JT. Clostridium difficile - more difficult than ever. N Engl J Med. 2008;359(18):1932-1940.
37. Aas J, Gessert CE, Bakken JS. Recurrent Clostridium difficile colitis: case series involving 18 patients treated with donor stool administered via a nasogastric tube. Clin Infect Dis. 2003;36(5): 580-585.

38. Lowy I, Molrine DC, Leav BA, et al. Treatment with monoclonal antibodies against Clostridium difficile toxins. $N$ Engl J Med. 2010; 362(3):197-205.

39. Hu MY, Katchar K, Kyne L, et al. Prospective derivation and validation of a clinical prediction rule for recurrent Clostridium difficile infection. Gastroenterology. 2009;136(4):1206-1214.

40. Sougioultzis S, Kyne L, Drudy D, et al. Clostridium difficile toxoid vaccine in recurrent $\mathrm{C}$. difficile-associated diarrhea. Gastroenterology. 2005;128(3):764-770.

41. Muto CA, Blank MK, Marsh JW, et al. Control of an outbreak of infection with the hypervirulent Clostridium difficile BI strain in a university hospital using a comprehensive 'bundle' approach. Clin Infect Dis. 2007;45(10):1266-1273.

42. Abbett SK, Yokoe DS, Lipsitz SR, et al. Proposed checklist of hospital interventions to decrease the incidence of healthcare-associated Clostridium difficile infection. Infect Control Hosp Epidemiol. 2009; 30(11):1062-1069.

43. Pittet D, Boyce JM. Hand hygiene and patient care: pursuing the Semmelweis legacy. Lancet Infect Dis. 2001;1:9-20.

44. Voss A, Widmer AF. No time for handwashing!? Handwashing versus alcoholic rub: can we afford $100 \%$ compliance? Infect Control Hosp Epidemiol. 1997;18(3):205-208.

45. Pittet D, Allegranzi B, Boyce JM; World Health Organization World Alliance for Patient Safety First Global Patient Safety Challenge Core Group of Experts. The World Health Organization guidelines on hand hygiene in health care and their consensus recommendations. Infect Control Hosp Epidemiol. 2009;30(7):611-622.

46. Allegranzi B, Pittet D. Role of hand hygiene in healthcare-associated infection prevention. $J$ Hosp Infect. 2009;73(4):305-315.

47. Oughton MT, Loo VG, Dendukuri N, Fenn S, Libman MD. Hand hygiene with soap and water is superior to alcohol rub and antiseptic wipes for removal of Clostridium difficile. Infect Control Hosp Epidemiol. 2009;30(10):939-944.

48. Gerding DN, Muto CA, Owens RC Jr. Measures to control and prevent Clostridium difficile infection. Clin Infect Dis. 2008;46 Suppl 1: S43-S49.

49. Mayfield JL, Leet T, Miller J, Mundy LM. Environmental control to reduce transmission of Clostridium difficile. Clin Infect Dis. 2000; 31(4):995-1000.

50. Wilcox MH, Fawley WN. Hospital disinfectants and spore formation by Clostridium difficile. Lancet. 2000;356(9238):1324.

51. Kaatz GW, Gitlin SD, Schaberg DR, et al. Acquisition of Clostridium difficile from the hospital environment. Am J Epidemiol. 1988; 127(6):1289-1294.

52. Fawley WN, Underwood S, Freeman J, et al. Efficacy of hospital cleaning agents and germicides against epidemic Clostridium difficile strains. Infect Control Hosp Epidemiol. 2007;28(8):920-925.

53. Howell MD, Novack V, Grgurich P, et al. Iatrogenic gastric acid suppression and the risk of nosocomial Clostridium difficile infection. Arch Intern Med. 2010;170(9):784-790.

54. Dial S, Delaney JA, Barkun AN, Suissa S. Use of gastric acidsuppressive agents and the risk of community-acquired Clostridium difficile-associated disease. JAMA. 2005;294(23):2989-2995.

55. Dial S, Delaney JA, Schneider V, Suissa S. Proton pump inhibitor use and risk of community-acquired Clostridium difficile-associated disease defined by prescription for oral vancomycin therapy. CMAJ. 2006;175(7):745-748

56. Aseeri M, Schroeder T, Kramer J, Zackula R. Gastric acid suppression by proton pump inhibitors as a risk factor for Clostridium difficileassociated diarrhea in hospitalized patients. Am J Gastroenterol. 2008;103(9):2308-2313.

57. Macfarlane GT, Macfarlane LE. Acquisition, evolution and maintenance of the normal gut microbiota. Dig Dis. 2009;27 Suppl 1:90-98. 
58. Kyne L, Sougioultzis S, McFarland LV, Kelly CP. Underlying disease severity as a major risk factor for nosocomial Clostridium difficile diarrhea. Infect Control Hosp Epidemiol. 2002;23(11): 653-659.

59. Leffler D, Cloud JW, Kelly CP. Gastric acid-suppressive agents and risk of Clostridium difficile-associated disease. JAMA. 2006;295(22): 2599-2600; author reply 2600-2601.

60. Dendukuri N, Costa V, McGregor M, Brophy JM. Probiotic therapy for the prevention and treatment of Clostridium difficile-associated diarrhea: a systematic review. CMAJ. 2005;173(2):167-170.
61. McFarland LV. Meta-analysis of probiotics for the prevention of antibiotic associated diarrhea and the treatment of Clostridium difficile disease. Am J Gastroenterol. 2006;101(4):812-822.

62. Plummer S, Weaver MA, Harris JC, Dee P, Hunter J. Clostridium difficile pilot study: effects of probiotic supplementation on the incidence of C. difficile diarrhoea. Int Microbiol. 2004;7(1):59-62.

63. Tung JM, Dolovich LR, Lee CH. Prevention of Clostridium difficile infection with Saccharomyces boulardii: a systematic review. Can J Gastroenterol. 2009;23(12):817-821.

\section{Publish your work in this journal}

Risk Management and Healthcare Policy is an international, peerreviewed, open access journal focusing on all aspects of public health, policy, and preventative measures to promote good health and improve morbidity and mortality in the population. The journal welcomes submitted papers covering original research, basic science, clinical \& epidemiological studies, reviews and evaluations, guidelines, expert opinion and commentary, case reports and extended reports. The manuscript management system is completely online and includes a very quick and fair peer-review system, which is all easy to use. Visit http://www.dovepress. com/testimonials.php to read real quotes from published authors.

Submit your manuscript here: http://www.dovepress.com/risk-management-and-healthcare-policy-journal 